\title{
Fish bone perforation of the duodenum
}

\section{Daisuke Murakamia, Hideaki Harada ${ }^{a}$, Yuji Amano ${ }^{b}$}

New Tokyo Hospital, Chiba, Japan

An 84-year-old woman presented to the emergency department with abdominal pain beginning immediately after the ingestion of mackerel. Her vital signs were normal. She had upper abdominal rebound tenderness and a white-cell count of 24,640 cells per cubic millimeter, with $90.7 \%$ neutrophils. Abdominal computed tomography revealed a linear, highdensity body in the third portion of the duodenum near the ligament of Treitz, and a small volume of free air in the vicinity (Fig. 1A). Emergency laparotomy could not obtain a surgical field sufficient to reveal the object. Intraoperative endoscopy successfully demonstrated a duodenal perforation due to a 3-cm-long fish bone, which was carefully removed by endoscopic forceps (Fig. 1B). Neither any sealing method, such as a surgical patch nor endoscopic closure, was done. Abdominal irrigation and treatment with antibiotics were undertaken. The patient was discharged without complications.

Less than $1 \%$ of gastrointestinal perforations are due to ingested bodies [1]. Several successful cases of conservative treatment with endoscopic retrieval for fish bone penetration have been reported [2,3]. Therefore, though only in patients whose condition is stable, minimally invasive treatments with early endoscopy are becoming more common as safe and alternative therapeutic methods to open surgery in

Department of a Gastroenterology (Daisuke Murakami, Hideaki

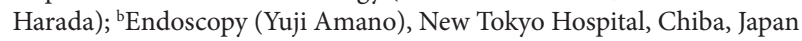

Conflict of Interest: None

Correspondence to: Daisuke Murakami, MD, MSc, Department of Gastroenterology, New Tokyo Hospital, Chiba, Japan, 1271 Wanagaya, Matsudo, Chiba, Japan, e-mail: daisuke.murakami@gmail.com

Received 24 December 2019; accepted 30 December 2019 published online 12 February 2020

DOI: https://doi.org/10.20524/aog.2020.0456

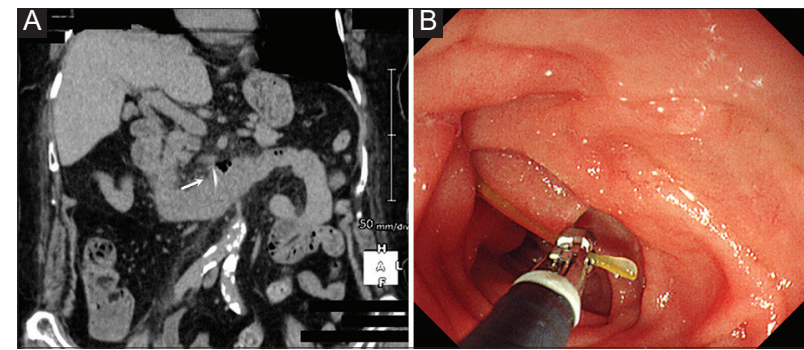

Figure 1 (A) Computed tomography of the abdomen showing the sharp foreign body penetrating the third portion of the duodenum near the ligament of Treitz. (B) Endoscopic view showing a yellow-colored fish bone, which was identified and carefully removed by endoscopic forceps

the treatment of minor gastrointestinal perforation [1]. In addition, the third portion of the duodenum is fixed to the retroperitoneum; consequently, the surgical approach may be limited by an insufficient view field to treat mesocolon with the mesenteric vessels, as in this case. Under certain conditions, minor fish bone perforation might be adequately treated by combining endoscopic removal with conservative treatment.

\section{References}

1. Ansari D, Torén W, Lindberg S, Pyrhönen HS, Andersson R. Diagnosis and management of duodenal perforations: a narrative review. Scand J Gastroenterol 2019;54:939-944.

2. Yuki T, Ishihara S, Okada M, et al. Double-balloon endoscopy for treatment of small bowel penetration by fish bone. Dig Endosc 2012;24:281.

3. Sasaki S, Nishikawa J, Saito M, et al. Endoscopic removal of a fish bone migrating and penetrating the stomach. Am J Gastroenterol 2018;113:1282. 